\title{
MKK4 as oncogene or tumor supressor: In cancer and senescence, the story's getting old
}

\author{
Steven C. Cunningham ${ }^{1}$, Eike Gallmeier ${ }^{2}$, and Scott E. Kern ${ }^{3}$ \\ ${ }^{1}$ Department of Surgery, St. Agnes Hospital, Baltimore, MD 21229, USA \\ ${ }^{2}$ Medizinische Klinik II, Klinikum der Universität München, Campus Großhadern, München, Germany \\ ${ }^{3}$ Department of Oncology, Johns Hopkins University, Baltimore, MD 21231, USA
}

E-mail: to Steven Cunningham at scunning@stagnes.org

The MKK4 gene is selected against by inactivating mutations in a large number of different tumor types, eg, tumors of the pancreas, bile ducts, breast, colon, lungs, testes [1-3] at a remarkably consistent rate of approximately $5-10 \%$ of tumors, identifying and defining it, therefore, as a tumor-suppressor (or genome-maintenance) gene [4].

Yet, experimental evidence exists that supports a prooncogenic role for MKK4 [5, 6]. Finegan and Tournier [6], for example, recently used an inducible murine model of MKK4 homozygous deletion to evaluate the role of MKK4 in skin tumorigenesis. They found that skin-specific MKK4-null mice were resistant to carcinogen-induced tumorigenesis. While the paper is well written and the model well designed, the fundamental premise may well be flawed, especially concerning MKK4's role in tumorigenesis, perhaps misleading the line of experimentation. There should be no question that MKK4 is tumor-suppressive, not oncogenic. MKK4 is widely selected against by tumors (its low rate of homozygous loss may be accounted for by a higher rate of heterozygous loss that could rationalize frequent $17 \mathrm{p}$ loss in diverse human cancers[7]) and unsurprisingly patients whose tumors have loss of MKK4 show statistically significant decrease in survival in the best controlled studies, using calibrated immunohistochemistry in large numbers of patients [8], consistent with a tumor-suppressive role.

Similarly consistent with a growth-suppressive role of MKK4 are observations made regarding the relationship between MKK4 and senescence. One of the ways MKK4 may suppress tumors is by inhibiting cell proliferation during replicative senescence, a widely re- cognized mechanism of tumor suppression. Marasa et al. [9] recently observed that MKK4 abundance increases in senescent fibroblasts. Overexpression of MKK4 decreased proliferation and promoted a senescent phenotype in young WI-38 human diploid fibroblasts and conversely, when MKK4 levels were lowered by several microRNAs targeting the MKK4 mRNA, the senescent phenotype was ameliorated and cells proliferated more rapidly [9]. In keeping with these observations, human tissue from older individuals was observed to express higher levels of MKK4 than corresponding tissue from young donors [9].

In the discussion of their inducible murine model of MKK4 homozygous deletion, Finegan and Tournier [6] rightly point out that there is conflicting literature regarding MKK4's role in tumorigenesis. The reason for the conflicting literature is largely because MKK4 is difficult to study experimentally. Their model would not be the first homozygous deletion model to model a population or a phenomenon that was not anticipated. For example, our own studies using homozygous MKK4-null cells engineered from the human pancreas cancer cell line PL-5 [10] showed that MKK4 deletion had a detrimental phenotype in a model of liver metastasis. Indeed experimental human data have shown that when tumors experiment with MKK4-null states, they are successful in developing a growth advantage allowing them to emerge through the clonal selection process in only $10 \%$ of cancers having $17 \mathrm{p}$ loss. We inferred from this observation that most tumor cells do not find the MKK4-null to be advantageous and that those PL-5 knock-out cells modeled this majority of cells. One may conclude from such a line of experimentation that the cell type-specific detrimental 
phenotype that was modeled offered an important counterweight to the selective advantage achieved by cells experimenting with genetic null states during tumorigenesis, the resultant balance determining the low but remarkably consistent rate of observed biallelic MKK4 mutations $[7,10]$.

Because changes effected to this gene may have advantageous or deleterious effects on cells depending on the model, cancer investigators must rely on real tumors and not artificial models to guide experimental design and interpretation such that valuable research time, energy, and funding are not spent studying a phenomenon, viz, a "pro-oncogenic" function of MKK4, that common cancer sense should tell us does not likely exist. To put it colloquially, it does not matter how scientists vote regarding a pro-oncogenic or tumor-suppressive role of MKK4, because the tumors have already conducted that election in favor of the latter: MKK4 must be a tumor suppressor, as concluded from observations on wide varieties of examined tumors, which uniformly present evidence of having selected for its loss at a consistent rate. There is no convincing evidence from observations of tumor biology that MKK4 has any pro-oncogenic role. Scientists may argue for such a role, but the tumors have had their say, age-old dictators that they are.

\section{REFERENCES}

1. Teng DH, Perry WL, 3rd, Hogan JK, Baumgard M, Bell R, Berry $S$, Davis T, Frank D, Frye C, Hattier T, Hu R, Jammulapati $S$, Janecki T, Leavitt A, Mitchell JT, Pero R, Sexton D, Schroeder $M$, Su PH, Swedlund B, Kyriakis JM, Avruch J, Bartel P, Wong AK, and Tavtigian SV. Human mitogen-activated protein kinase kinase 4 as a candidate tumor suppressor. Cancer Res. 1997; 57: 41774182.

2. Su GH, Hilgers W, Shekher MC, Tang DJ, Yeo CJ, Hruban RH and Kern SE. Alterations in pancreatic, biliary, and breast carcinomas support MKK4 as a genetically targeted tumor suppressor gene. Cancer Res. 1998; 58: 2339-2342.

3. Parsons DW, Wang TL, Samuels $Y$, Bardelli A, Cummins JM, DeLong L, Silliman N, Ptak J, Szabo S, Willson JK, Markowitz S, Kinzler KW, Vogelstein B, Lengauer C, and Velculescu VE. Colorectal cancer: mutations in a signalling pathway. Nature. 2005; 436: 792.

4. Fearon ER Tumor-Suppressor Genes. In: B. Vogelstein and K. W. Kinzler (eds.), The Genetic Basis of Human Cancer, 2nd edition, pp. 197-206. New York: McGraw-Hill, 2002.

5. Wang L, Pan $Y$ and Dai JL. Evidence of MKK4 pro-oncogenic activity in breast and pancreatic tumors. Oncogene. 2004; 23: 5978-5985.

6. Finegan KG and Tournier $C$. The mitogen-activated protein kinase kinase 4 has a pro-oncogenic role in skin cancer. Cancer Res. 70: 5797-5806.

7. Cunningham SC, Gallmeier E, Hucl T, Dezentje DA, Abdelmohsen K, Gorospe M and Kern SE. Theoretical proposal: allele dosage of MAP2K4/MKK4 could rationalize frequent $17 p$ loss in diverse human cancers. Cell Cycle. 2006; 5: 1090-1093.

8. Cunningham SC, Kamangar F, Kim MP, Hammoud S, Haque R, lacobuzio-Donahue C, Ashfaq R, Kern SE, Maitra A, Heitmiller RE, Choti MA, Lillemoe KD, Cameron JL, Yeo CJ, Montgomery E, and Schulick RD. Mkk4 Status Predicts Survival after Resection of Gastric Adenocarcinoma. Arch Surg. 2006; 141: 1095-1099.

9. Marasa BS, Srikantan S, Masuda K, Abdelmohsen K, Kuwano Y, Yang X, Martindale JL, Rinker-Schaeffer CW and Gorospe M. Increased MKK4 abundance with replicative senescence is linked to the joint reduction of multiple microRNAs. Sci Signal. 2009; 2: ra69.

10. Cunningham SC, Gallmeier E, Hucl T, Dezentje DA, Calhoun ES, Falco G, Abdelmohsen K, Gorospe M and Kern SE. Targeted deletion of MKK4 in cancer cells: a detrimental phenotype manifests as decreased experimental metastasis and suggests a counterweight to the evolution of tumor-suppressor loss. Cancer Res. 2006; 66: 5560-5564. 